\title{
How The Current Practice of Learning Instruction Engages Engineering Students into Learning in Edinburgh College?
}

\author{
Daniel Erasto Santos Reyes ${ }^{1,}$ Aileen McGuigan² \\ ${ }^{1}$ School of Engineering, Edinburgh College, Scotland, UK \\ ${ }^{2}$ School of Education and Social Work, University of Dundee, Scotland, UK
}

\begin{abstract}
Over the last few decades, significant progress has been achieved by educational researchers in developing an understanding of the nature of learning, across settings, and identifying principles which have enabled educators to design and develop learning and assessment approaches more effectively. This design research project addressed the following: How does the current practice of learning instruction or activity engage students or their attention in such a way that keeps the students' interest in it and gets them actively involved in it? In order to approach the research problem, three research questions were formulated in order to focus data gathering: How successful is the current practice in directing or guiding students to appropriate learning activities or specific engineering knowledge? How effective is the existing practice of learning activity in promoting the acquisition of specific engineering knowledge or skills? How appealing is the existing practice of learning activity to engineering students? A qualitative research methodology was used to approach the research problem. Semi-structured interviews, observations, and artefact analysis were the main procedures used to obtain data. This paper presents only the results of the interview procedures. The interview transcripts coding evolved into six major themes and one concept that intend to reflect what works well in Edinburgh College (EC) engineering classroom learning. These major themes and concept represent valuable engineering students' voices that will be communicated to the relevant stakeholders and will inform design for learning activities in order to create new learning approaches. It is hoped that these will improve the current practice of teaching and learning in this educational setting.
\end{abstract}

Keywords: design research, design for learning, instructional strategies, instructional design, students' voice. 


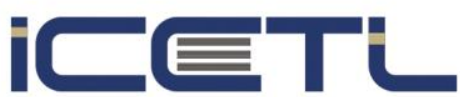

21-23 FEBRUARY, 2020

\section{$3^{\text {rd }}$ International Conference on Research in EDUCATION, TEACHING and LEARNING}

ROME, ITALY

\section{Introduction}

In general, over the last few decades, significant progress has been achieved by educational scientists in developing an understanding of the nature of learning, across settings, and describing principles which have enabled educators to design curriculum, and to approach learning and assessment more effectively (Donovan et al., 2000; NASEM, 2018; Lee, 2017). Motivated by the need to understand students' learning experiences, expectations, and employment aspirations, researchers have focused on gathering the voice of students at all levels of education (Cook-Shather et al., 2014; Hamalainen et al., 2017; Borup and Stevens, 2017; van der Kleij et al., 2017). The students' views on their learning and teaching plays an important role in implementing actions in order to enhance students' engagement and transforming the learning environment.

In particular, and traditionally, EC engineering groups consist of students with a large variety of preferences, expectations and needs. Many of these students left school with minimum qualifications and generally achieved a low level of performance, thus were unable to gain access to university. Many other students seek to improve some basic skills in order to have access to apprenticeships or employment rather than following traditional more academic career paths. Often, these groups include a few mature students who are returning to education following many years working in industry. These students have extensive hands-on experience, but very little in the way of analytical skills. Also, international students make up engineering classes. They bring further varying factors to classrooms, including differences in language, previous learning experiences and educational background and expectations. Given this, classroom learning and teaching poses significant challenges and opportunities for all involved and interested in enhancing student learning in the college. This design research project approached the following research issue: How does the current practice of learning instruction or activity engage students or their attention in such a way that keeps the students' interest in it and gets them actively involved in it? The remaining sections of this paper describe the relevant research issues, the overall research methodology and procedures, the main results and discussion from the emerging themes and concept from interview data, and finally some relevant conclusions and future work are presented.

\section{Research issues}

\subsection{Science of learning and instruction}

Instructional science began as an offshoot of the dominant theories of learning, such as behaviourism, cognitivism, and constructivism which were developed primarily by psychologists (Peters, 2014). They developed a connection between findings of psychology and their practical application in learning. Behaviourist learning strategies involve primarily recalling facts, generalisations, associations, and chaining. Now, it is recognised by scholars that usually they cannot be used by teachers and students to approach learning activities, such as problem-solving and critical thinking (Omrod, 2012; Schunk, 2012; Ertmer and Newby, 2013). It is recognised by both researchers and practitioners, including policy makers, that 


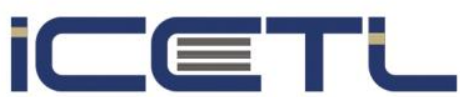

21-23 FEBRUARY, 2020

\section{$3^{\text {rd }}$ International Conference on Research in EDUCATION, TEACHING and LEARNING}

ROME, ITALY

teaching centred strategies might compromise the effectiveness of student learning (Andres, 2019). On the other hand, cognitivist learning strategies involve cognitive processing strategies in order to transfer knowledge to students in the most efficient and effective manner (Omrod, 2012; Schunk, 2012; Ertmer and Newby, 2013; Dinsmore and Zoellner, 2018). Both behaviourist and cognitivist learning strategies use feedback either to reinforce or correct learning performance (van Blanckestein et al., 2019; Asterthan and Dotan, 2018). A predominant line of thought of constructivist theory of learning is that learning strategies should enable students to elaborate on and interpret information from a given real life situation or context (Omrod, 2012; Schunk, 2012; Ertmer and Newby, 2013; Alt, 2017). In order for these strategies to be successful, they must involve students in an authentic real-life situation in order to practise and construct knowledge (Kfai and Burke, 2015). In addition to this, the science of learning makes clear distinctions between how young and adult learners learn (Sharif et al., 2017).

More recently, researchers investigating the mechanisms of learning have generated new findings about neural processes involved in learning, and how various factors, such as cultural and learning environments affect learning, as well as identifying relevant technologies that offer potential applications in promoting learning (NASEM, 2018; Lee, 2017). For example, information processing is the prevailing learning theory in cognitive psychology. Long-term memory, working memory, cognitive load, cognitive theory of multimedia learning, and selfregulated learning are amongst others learning theories that are translated into instructional strategies in order to process topic content more efficiently and effectively (Khalil and Elkider, 2016; Wang et al., 2018; Korbach et al., 2017; Seufert et al., 2017; Winne, 2018; Desiron et al., 2018; Scheiter et al., 2018). These theories attempt to explain how knowledge is acquired and thus enable teachers/instructional designers to develop learning instructions or activities.

\subsection{Design for learning}

While instructional science is concerned with the discovery of instructional strategies or learning strategies (Merril et al., 1996), design for learning or instructional design is founded in the science of instruction (Peters, 2014; Reiser, 2001a; Reiser, 2001b). Instructional design as a design process involves designing and developing instructional material, lessons, and other relevant learning systems using science-based principles and procedures in order to produce more effective and appealing instructions (Merril et al., 1996; Molenda et al., 2003; Lameras et al., 2017; Harnandez-Leo et al., 2019; Mor and Abdu, 2018; Lewin et al., 2018). Just like product design or design thinking, the instructional design process involves various steps or stages, such as analysis, design, development, implementation, and evaluation (Khalil and Elkhider, 2016; Jonassen, 2019). At the early stages of the design process, designers or teachers develop a deep understanding of students' needs, in order for them to develop new learning approaches that are relevant, useful and desirable to students (Hamalainen et al., 2017; Borup and Stevens, 2017). For example, design research is used to explore and understand, and find ways to potentiate human learning (Chang et al., 2013; Cole and Parker, 2016; Gutierrez and Jurow, 2016; Lan et al., 2018; Sannino et al., 2016). With the use of 


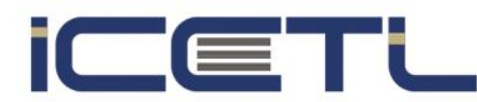

21-23 FEBRUARY, 2020

\section{$3^{\text {rd }}$ International Conference on Research in EDUCATION, TEACHING and LEARNING}

ROME, ITALY

design research methods designers intend to frame the design problem by discovering students' needs. The ultimate purpose of design for learning is not only integrating these needs, but also integrating the instructional strategies discovered by instructional science into new learning approaches. In line with this, via design research, this research project addressed the following research issue: How does the current practice of learning instruction or activity engage students or their attention in such a way that keeps the students' interest in it and gets them actively involved in it?

\section{Overall methodological approach}

\subsection{Methodological approach}

The following questions, as discussed by Grix (2002) and Krauss (2005), were used in order to frame the methodological approach: what is there to know? What and how can the researcher know about the particular situation? How can the researcher know about acquiring that knowledge? Which precise procedures can the researcher use to acquire it? And which data can the researcher collect? Regarding the first two questions, the position taken by the researchers in this project with respect to the nature of the EC engineering classroom learning and what constitutes acceptable knowledge is interpretivist. The researchers sought to find out about subjective meanings and motivating actions occurring in a typical engineering classroom. How can we know about acquiring that knowledge? Via an appropriate qualitative research methodology, it was intended to capture rich details about how EC engineering students construe their learning experiences, how they create their worlds, and what meaning they attribute to their experiences in day-to-day classroom activities. Which precise procedures can the researcher use to acquire data? Interviews, observations, and artefact analysis were used with the aim of producing rich and descriptive data in order to build empathy and develop a thorough understanding of EC engineering students' learning. Interviews were carried out in a location where students perform their learning activities. This enabled the researchers to ask questions about the issues of interest in their natural learning environment. The researchers listened to what students said, and observed what they did and analysed students' work in order to gain an in-depth understanding of their current learning experience. This multiple source of data helped to improve the rigor and trustworthiness of the data. Finally, which data could the researcher collect? This research project gathered three types of data: (a) interview transcripts, (b) observation transcripts, and (c) artefact analysis transcripts. These types of data were used to conduct two cycles of coding according to Saldana (2013). Throughout the first cycle Attribute Coding, Initial Coding, Descriptive Coding, Versus Coding and in Vivo Coding techniques were used in order to organize, manage, and to code the data gathered from the interviews, observations, and artefact analysis.

It was necessary to combine these coding techniques with the aim of breaking down qualitative data into discrete parts, examining them and identifying similarities and differences. Also, this helped to identify the actual participant's own words or short phrases 


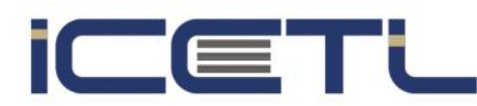

21-23 FEBRUARY, 2020

\section{$3^{\text {rd }}$ International Conference on Research in EDUCATION, TEACHING and LEARNING}

ROME, ITALY

that related to the research questions. The authors conducted a four-cycle code mapping in order to classify, integrate and conceptualize the themes or categories that emerged from the first cycle coding. The major themes and patterns produced in the four-cycle code mapping are sufficient to inform design thinking for the design and development of future instructional activities or procedures.

\subsection{Research procedures}

The research questions stated above and the purposeful sampling guidelines suggested by Benoot et al. (2016) and Palinkas et al. (2015) were the best approach to follow when selecting volunteer participants from a wide range of learning experience within the engineering department. Ten semi-structured interviews were conducted in a location where students perform their learning activities and conducted as a natural conversation. For each interview, the researchers made notes of which participant was being interviewed using a participant number. Data analysis was carried out in parallel with data collection and when no new information was produced from the interview transcripts, then the sampling activity stopped. As the analysis of the data gathered was progressing, the coding techniques used throughout were documented and the triangulation technique suggested by Merriam and Tisdell (2015) was used as a means to ensure trustworthiness and credibility of the results. Preliminary coded data was forwarded to the second author to determine or compare what is similar and what changes. Furthermore, the final interview transcript codes, themes and concept were shown to one of the research participants for final comments and feedback. In this research project, the researchers by all means ensured the privacy and confidentiality of all participants according to the Data Protection Act (2018) and the University of Dundee's research ethics requirements (2018).

\section{Results and discussion}

\subsection{Themes from the interview data}

In analysing the interview data, six major themes and one concept became apparent (Figure 1). After some reflections on the major themes, it is concluded that a concept that amalgamates these themes is effective engineering learning, since effective implies successful, efficient, productive, valuable, and useful. The various themes evolving from the interview transcripts can be attributed to effective engineering learning. Subthemes can be written in several places if they relate to several major themes. These themes have the greatest impact on engineering learning. Similarly, various subthemes, as derived directly from the interview transcript codes, are attributed to each major theme. In this way, the major themes and subthemes, and the concept shown in Figure 1 are contextually grounded in a typical engineering classroom at EC. 


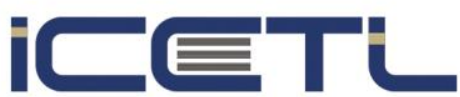

21-23 FEBRUARY, 2020

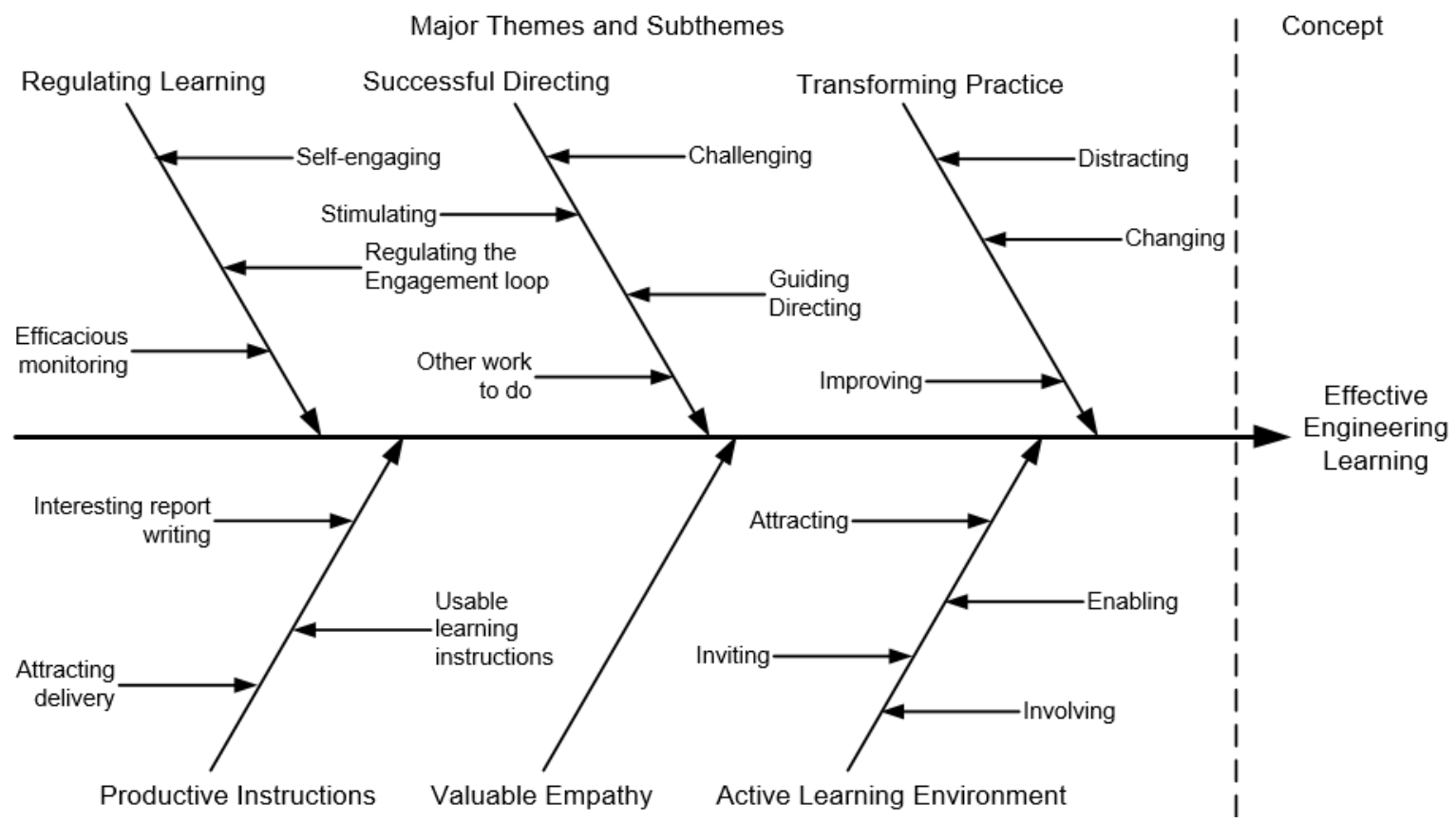

Figure 1 Emerging concept and major themes.

Effective engineering learning seems to be an umbrella code for active learning environment, successful directing, valuable empathy, regulating learning, productive instructions, and transforming practice. One of the research participants said "here to better yourself" referring to college students. Students enrolled in engineering courses at EC are here to develop knowledge and skills related to mechanical, systems, electrical, renewable and other relevant engineering subjects. The salient effective code focuses on the particular by using engineering to represent all students doing engineering courses at the EC. In this sense, Effective engineering learning brings together what works well and what produces what students expect or want.

Similarly, active learning environment is a type of umbrella concept that becomes apparent from inviting, involving, enabling, and attracting subthemes. In analysing the interview transcripts, the data reveals that students joined the engineering courses with great expectations to "experience new things" and to "learn something new" in a new learning environment where they can become leaders of their own learning. The active learning environment code is general enough to include not only classrooms and workshops but all spaces that enable students to be actively doing things and thinking about them. Reflecting on the interview data, an active learning environment invites, involves, attracts and enables students to "be in charge of [their] own learning". This refers to a learning environment that departs from past learning experiences, i.e., "know it, from past, from basic, from school". More specifically, it arrests students' attention by focussing on their learning needs, challenging their thinking, working, and learning new specific engineering knowledge and skills. It draws students' attention to get actively involved in their own learning, and "working outside classrooms" in order to "get a feel for things" and "understand how it works". It 


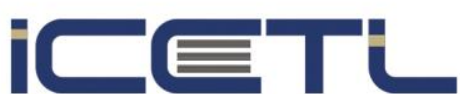

21-23 FEBRUARY, 2020

\section{$3^{\text {rd }}$ International Conference on Research in EDUCATION, TEACHING and LEARNING}

ROME, ITALY

attracts students' attention by offering them opportunities to use things that produce "great experience using different software and stuff" and other related information technology. It catches students' attention by enabling them to use "cool pieces of equipment" which cause them to "enjoy experiments".

Next, successful directing emerges from the following codes: challenging, guiding/directing, stimulating, and other work to do. Again, reflecting on the interview data, engineering students effectively are engaged in their learning when lecturers point in the right direction of what students should do or accomplish. When students are given tasks to do, they think "it's great", "rather than just learning from the board". Regarding the challenging code appropriately indicates that students enjoy challenges, and challenges do not come much bigger than real-life engineering applications. EC engineering students not only enjoy "seeing it how it could be applied elsewhere", "calculation examples a bit like real life" and "how it would like to real life and how use it", but the "more difficult" the "more fun". Similarly, guiding/directing code refers to lecturers advising, guiding or directing students to the appropriate learning activities in order to acquire specific engineering knowledge and skills. Again, students embark on learning when lecturers are "quite consistent with presentations" as well as demonstrating explanations with "really good examples" and directing students into practice in order to enhance learning. The stimulating subtheme embodies lecturers' learning activities that encourage students to use a variety of engineering technology, such as the computer aided draughting (CAD) software in order to make more vivid students' learning experience, e.g., "CAD class, that sort of thing was really good". Another relevant code that the interview transcripts reveal is other work to do, as one of the research participants emphasised: "lecturers are quite good at saying if you've finished the work", then "you can do stuff for other classes".

Valuable empathy theme appropriately evolves from the interview passages and codes. According to the interviewees, a successful engagement into learning depends on a good rapport between the lecturer and the students. This subtheme rightly acknowledges students' strong appreciation of the importance of mutual engagement into learning activities. The following codes reflect this: "he gets to understand what we want", "we also understand what he'd like", "he needs for us to do the work", "but bend and shape it to be more suitable". As the research participants emphasise, if the lecturer and the students themselves have a rapport, they have a good relationship which helps them to understand very well each other's needs or wants.

The productive instruction major theme emerges from the following subthemes: attracting delivery, usable learning instructions, and interesting report writing. In analysing the interview transcripts and their corresponding codes, e.g., "PowerPoint clear and well structured", "quite consistent with presentations", "got the whole slide up and follows it quite consistently", teacher "does it on the screen", "talks through them really well", "we follow example", then "do tasks without guidance" attract students' attention. In this sense, attracting delivery reflects classroom presentations and lesson delivery. Similarly, usable learning instructions emerges from the interview transcripts and codes, e.g., interviewees from 


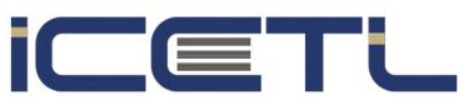

21-23 FEBRUARY, 2020

\section{$3^{\text {rd }}$ International Conference on Research in EDUCATION, TEACHING and LEARNING}

ROME, ITALY

different courses and levels agree that CAD "tutorials were quite straight forward" to use or to follow. This subtheme involves not only easy to use learning instructions, but also entails effectiveness, efficiency, and engagement. In the case of CAD instructions, students complete their learning tasks with a very high degree of accuracy. Most students in a class produce the exact replica of the intended engineering model. In this sense, CAD instructions are very effective. Because these instructions are easy to follow, students are effective in achieving tasks. One of the interviewees said CAD "tutorials were very well laid out". This engages students because CAD instructions are enjoyable and satisfying to use. Engaging instructions also entails aesthetics, more specifically CAD instructions look right with proper layouts and lots of graphic design elements which attract students' attention. It seems that students find report writing beneficial because it "helps understand a little more", according to one of the interviewees. Writing stories on different engineering topics fascinates students and, in this way, they gain new knowledge or further improve their existing knowledge or skills. But the true intention of the interesting report writing code is to represent the idea of writing a story of an engineering topic about "something I want to", "more suited to each [student]". This is an interesting finding of this research project, since currently our engineering students are given topics, and often they are provided with a detailed prescription on how to complete a report writing activity. In this sense, productive instruction major theme intends to reflect a learning environment that is fruitful and beneficial in the acquisition of specific and appropriate engineering knowledge and skills.

Regulating learning is another umbrella type of theme that emerges from self-engaging, efficacious monitoring, and regulating the engagement loop, and these in turn emerged from various interview passages and their corresponding coding. Self-engaging subtheme intends to reflect the students' disposition to carry out learning tasks without significant supervision or within a rigid and rigorous classroom environment. "Work at your own pace" is the "sort of learning" that the students like. This sort of learning liberates students from classroom rules and restrictions imposed by the pace of classmates, e.g., "didn't have to wait for others to catch up", didn't worry about someone behind". In addition to students' willingness to do learning tasks without rigid rules, it seems that they prefer self-guidance, i.e., "come up with my own steps" instead of the lecturer's guidance or initiative. They prefer to take part in the design of their learning instructions rather than following rigid or not easy to follow instructions. This, produces better outcomes and above all this engages students into their own learning. Efficacious monitoring subtheme involves formative assessment, summative assessment, and related means for monitoring students' learning performance. Students view regular assessments as "a good opportunity to see where you are at the moment", "you can see how you are getting on" and identify student's learning needs. However, as emphasised by another student, who prefers to learn "new things", thinks that assessments did not help to achieve this. It seems that the current practice of monitoring learning is mostly about memorising, as indicated by "study for the assessment", "just to pass the exam", "it is a memory thing". Monitoring is not only about diagnosing and identifying learning needs of students, but also involves instruction. Learning performance monitoring is an ongoing cycle in the interaction between the instruction and learning process. It is for this reason that this 


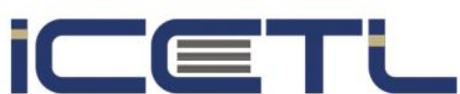

21-23 FEBRUARY, 2020

\section{$3^{\text {rd }}$ International Conference on Research in EDUCATION, TEACHING and LEARNING}

ROME, ITALY

sub-theme is called efficacious monitoring. Both formative and summative assessments, including all those means of monitoring learning progress should produce the intended results. Finally, regulating the engagement loop subtheme is closely related to the code efficacious monitoring and the valuable empathy subtheme presented above. This intends to regulate or control "the way lecturer engages" students and "the way students engage" with learning. This suggests that an enjoyable class works well when both the lecturer and the student engage into the learning process. Here, this is the meaning given to regulating the engagement loop code. This may be another interesting finding of this research project, and thus an opportunity for implementing an effective control loop in order to foster an enjoyable learning activity in the classroom.

Transforming practice is the last major theme that emerged from this preliminary interview data analysis (Figure 1). It emerged from distracting, changing, and improving codes. Distracting code indicates that boring learning activities or instructions distract students' attention from learning, e.g., "mates around me on their phones", "write down, memorise", "it is so tedious". The use of mobile technology for purposes other than learning may be a signal that students find learning activities or instructions boring, tedious or tiring. This also distracts other students' attention and may result in unproductive, ineffective and inefficient learning activities. Students, according to one of the research participants, prefer to get involved into learning activities rather than "sit back and not doing anything". Furthermore, reflecting on "think about it", students favour learning activities in which they are actively involved in considering, reflecting, and deliberating about specific new engineering knowledge. Distracting is strongly related to other subthemes discussed above such as other work to do, valuable empathy, and subthemes of successful directing. The most important notion embedded in the changing code is that of difference. Either that students come from school, or are returning to education after some time in working experience, or are coming from another country, they expect a different learning environment in relation to their past experience. As some of the codes from the interview transcripts reflect it: "nothing unusual" in the current college learning environment. It seems that students come to college with expectations of change. However, the current college learning environment is "a lot like school". They not only expect an exciting change, in a new learning environment, but also, they expect new things, new knowledge, new ways of learning, and new learning experiences. Similarly, this code refers to all those activities related to classroom organisation and management. Students find it difficult to cope with changes in timetables, e.g., "lots of changing in the schedule", "changing and teachers", "constantly finding in new classroom or new teacher". Similarly, improving highlights that there are some aspects of instruction and learning activities that require change in order to make them better. There are cases that learning instructions emphasise on "write down, memorise" and students do the "same thing over and over again". The use of the same topics or learning materials in different course levels is another important issue identified in this analysis. Finally, the interview data reveals that there is currently an imbalance between theoretical and practical demonstration of engineering principles, e.g., "lots of theoretical work", "no opportunity to get on equipment", "took three years to get on a lathe or a mill". 


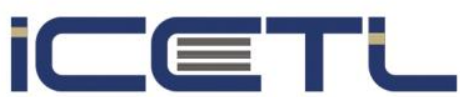

21-23 FEBRUARY, 2020

\section{$3^{\text {rd }}$ International Conference on Research in EDUCATION, TEACHING and LEARNING}

ROME, ITALY

\subsection{Discussion}

According to the above results, the predominant practice of instruction in the EC engineering department at Midlothian campus is an amalgamation of the three dominant theories of learning namely behaviourism, cognitivism, and constructivism. The productive instruction theme reflects the use of learning objectives in order to direct students, within a conditioned engineering classroom environment, to produce the desired results, to achieve assessments, and to provide appropriate feedback either to reinforce what works well or to provide corrective actions as necessary. This is primarily a behaviourist approach to learning (Schunk, 2012; Ertmer and Newby, 2013; Kay and Kibble, 2016). Content delivery attracts students' attention, in particular when lecturers provide clear expert guidance, which helps students to focus on the topics of study (Cook-Shather et al., 2014; Lazarides et al., 2019). Delivery becomes more attractive to students when they are given opportunities to gradually develop their problem-solving skills. This practice is supported by cognitive learning approaches (Khalil and Elkhider, 2016). Moreover, content delivery is presented in such a way that it is assimilated by the student within a given time frame and classroom learning environment that agrees with other research findings (Anmarkrud et al., 2019). However, the active learning environment major theme reflects students' voices for more constructivist approaches to design for learning. Constructivist learning instructions emphasise on the active role of students in constructing new knowledge as they interact with problem situations in a wider real-life environment (Kay and Kibble, 2016; Khalil and Elkhider, 2016). Just like in cognitivist approaches to learning (Khalil and Elkhider, 2016), EC engineering lecturers direct students to appropriate learning activities in order to stimulate their cognitive skills. Nevertheless, students prefer to be actively involved in doing than listening, which effectively engages them into their own learning. However, the valuable empathy major theme suggests that student engagement depends on a good relationship between students and lecturer; this is, lecturers should develop a good understanding of students' needs or wants and incorporate these needs into instruction in such a way that they engage students' attention. Furthermore, the interaction between student and lecturer is a dynamic process of transformation. This requires an effective control system. This idea is embodied in regulating learning major theme. This is an interesting finding of this design research project. It is an interesting finding because it reflects what EC engineering students enjoy about learning. Interview data suggests that students are happy to engage into learning without rigid classroom rules and restrictions imposed by classmates. Self-regulated learning theory (Winne, 2018; Scheiter et al., 2018) supports this, but little is known about how to control the whole process of learning. This requires further review of existing literature, and possible further research, in order to expand and develop this idea. This idea departs from the traditional idea of controlling the stimulusresponse relationship within a learning environment (Schunk, 2012; Ertmer and Newby, 2013; Khalil and Elkhider, 2016). 


\section{$3^{\text {rd }}$ International Conference on Research in EDUCATION, TEACHING and LEARNING}

\section{Conclusion and future work}

This paper presented one concept that embodies six major themes that reflect what works well and what does not engage EC engineering students into learning. These results have significant implications for practice and policy makers of EC. Future work includes disseminating these findings to relevant stakeholders and to carrying out design for learning activities in order to implement these design research recommendations.

\section{References}

Alt, D. (2017). College students' perceived learning environment and their social media engagement in activities unrelated to classwork. Instructional Science. 45, 623-643.

Andres, H.P. (2019). Active teaching to manage course difficulty and learning motivation. Journal of Further and Higher Education. Vol. 43, No. 2, 220-235.

Anmarkrud, Ø., Andresen, A., and Braten, I., (2019). Cognitive load and working memory in multimedia learning: conceptual and measurement issues. Educational Psychologist. 54:2, 61-83, DOI:10.1080/00461520.2018.1554484.

Asterthan, C.S.C., and Dotan, A. (2018). Feedback that corrects and contrasts students' erroneous solutions with expert ones improves expository instruction for conceptual change. Instructional Science. Volume 46, Issue 3, 337-335.

Benoot, Ch., Hannes, K. and Bilsen, J., (2016). The use of purposeful sampling in a qualitative evidence synthesis: A worked example on sexual adjustment to a cancer trajectory. BCM Medical Research Methodology. 16-21.

Borup, J., and Stevens, M.A. (2017). Using student voice to examine teacher practices at a cyber charter high school. British Journal of Educational Technology. Vol. 48, No. 5, 11191130 .

Chang, B., Chuan, M.-T., and Ho, S. (2013). Understanding students' competition preferences in multiple-mice supported classroom. Educational Technology and Society. 16(1), 171-182.

Cole, M. and Packer, M. (2016). Design-based intervention research as the science of the double artificial. Journal of the Learning Sciences. 25, 503-530.

Cook-Shather, A., Bovil, C., and Felten, P. (2014). Engaging students as partners in learning and teaching: A guide for faculty. San Francisco, CA: Jossey-Bass.

Data Protection Act 2018. (2018, November 15). Legislation UK. Data Protection Act 2018. http://www.legislation.gov.uk/ukpga/2018/12/contents.

Desiron, J.C., Vries, E., Bartel, A.N., and Varahamurti, N. (2018). The influence of text cohesion and picture detail on young readers' knowledge of science topics. British Journal of Educational Psychology. 88, 465-479. 


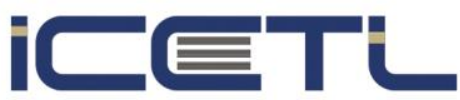

21-23 FEBRUARY, 2020

\section{$3^{\text {rd }}$ International Conference on Research in EDUCATION, TEACHING and LEARNING}

ROME, ITALY

Dinsmore, D.L., and Zoellner, B.P. (2018). The relation between cognitive and metacognitive strategic processing during a science simulation. British Journal of Educational Psychology. 88, 95-117.

Donovan, M.S., Bransford, J.D., and Pellegrino, J.W. eds., (2000). How People Learn: Brain, Mind, Experience, and School. Washington, D.C.: The National Academy Press.

Ertmer, P.A. and Newby, T.J. (2013). Behaviourism, Cognitivism, Constructivism: Comparing Critical Features from an Instructional Design Perspective. Performance Improvement Quarterly. 26(2), 43-71.

Grix, J. (2002). Introducing students to the generic terminology of social research. Politics. Vol. 22(3), 175-186.

Gutierrez, K.D., and Jurow, A.S., (2016). Social design experiments: toward equity by design. Journal of the Learning Sciences. 25, 565-598.

Hamalainen, R., Kiili, C., and Smith, B.E. (2017). Orchestrating $21^{\text {st }}$ century learning in higher education: A perspective on student voice. British Journal of Educational Technology. Vol. 28, No.5, 1106-1118.

Hernandez-Leo, D., Martinez-Maldonado, R., Pardo, A., Munoz-Cristobal, J.A., and Rodriguez-Triana, M.J. (2019). Analytics for learning design: A layered framework and tools. British Journal of Educational Technology. Vol. 50, No. 1, 139-152.

Jonassen, D.H., (2019). Technology as Cognitive Tools: Learners as Designers [online]. [Viewed 8 March 2019]. DOCPLAYER. Available from: https://docplayer.net/35157767Technology-as-cognitive-tools-learners-as-designers.html.

Kay, D., and Kibble, J., (2016). Learning theories 101: application to everyday teaching and scholarship. Advances in Physiology Education. 40, 17-25.

Kfai, Y., and Burke, Q. (2015). Constructionist Gaming: understanding the benefits of making games for learning. Educational Psychologists. 50(4), 313-334.

Khalil, M.K., and Elkhider, I.A. (2016). Applying learning theories and instructional design models for effective instruction. Advances in Physiology Education. 40, 147-156.

Korbach, A., Brunken, R., and Park, B. (2017). Measurement of cognitive load in multimedia learning: a comparison of different objective measures. Instructional Science. 45, 515-536.

Krauss, S.E. (2005). Research paradigm and meaning making. A primer. The Qualitative Report. Volume 4, Number 4. December 2005, 758-770.

Lameras, P., Arnab, S., Dunwell, I., Stewart, C., Clarke, S., and Petridis, P. (2017). Essential features of serious games design in higher education: linking learning attributes to game mechanics. British Journal of Educational Technology. Vol. 48, No. 4, 972-994. 


\section{$3^{\text {rd }}$ International Conference on Research in EDUCATION, TEACHING and LEARNING}

Lan, Y.-J., Hsiao, I.Y.T., and Shih, M-F. (2018). Effective learning design of game-based 3D virtual language learning environments for special educations students. Educational Technology \& Society, 21(3), 213-227.

Lazarides, R., Gaspard, H., and Dicke, A-L. (2019). Dynamics of classroom motivation: Teacher enthusiasm and the development of math interest and teacher support. Learning and Instruction, 60, 126-137.

Lee, C.D. (2017). Expanding visions of how people learn: the centrality of identity repertoires. Journal of the Learning Sciences. 26, 517-524.

Lewin, C., Cranmer, S. and McNicol, S. (2018). Developing digital pedagogy through learning design: An activity theory perspective. British Journal of Educational Technology. Vol. 49, No. 6, 1131-1144.

Merriam, Sharan B., and Tisdell, E. J., (2015). Qualitative Research: A Guide to Design and Implementation. $4^{\text {th }}$ Edition. John Wiley and Sons.

Merrill, M.D., Drake, L., Lacy, M., and Pratt, J. (1996). Reclaiming Instructional Design. Educational Technology. 36(5), 5-7.

Molenda, M.Reigeluth, C.M., an Nelson, L.M. (2003). Instructional design. In: Nadel, L., (ed.). Encyclopedia of Cognitive Science. Nature Publishing Group, 574-578.

Mor, Y. and Abdu, R. (2018). Responsive learning design: epistemic fluency and generative pedagogical practices. British Journal of Educational Technology. Vol. 49, No. 6, 1162-1173.

National Academies of Science, Engineering and Medicine. (2018). How People Learn II: Learners, Contexts, and Cultures. Washington, DC: The National Academies Press.

Omrod, J.E. (2012). Human Learning. $6^{\text {th }}$ edition. Pearson.

Palinkas, L.A., Horwitz, S.M., Green, C.A., Wisdom, J.P., Duan, N. and Hoagwood, K., (2015). Purposeful sampling for qualitative data collection and analysis in mixed method implementation research. Adm Policy Ment Health. 42(5), 533 - 544.

Peters, M.A. (2014). The shapes of theory in education. Educational Philosophy and Theory. 46:12 46:12. 1315-1319. [Viewed 10 May 2019]. Available from: DOI: 10.1080/00131857.2014.920975.

Reiser, R.A. (2001a). A history of instructional design and technology: Part I: a history of instructional media. Educational Technology Research and Development. Vol. 49, No. 1, 5364.

Reiser, R.A. (2001b). A history of instructional design and technology: Part II: a history of instructional design. Educational Technology Research and Development. Vol. 49, No. 2, 57 67.

Saldana, J. (2013). The coding manual for qualitative researchers. 2th ed. London: SAGE. 


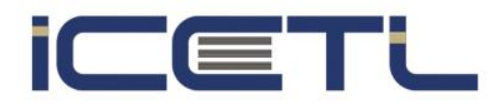

21-23 FEBRUARY, 2020

\section{$3^{\text {rd }}$ International Conference on Research in EDUCATION, TEACHING and LEARNING}

ROME, ITALY

Sannino, A., Engestrom, Y., and Lemos, M., (2016). Formative interventions for expansive learning and transformative agency. Journal of the Learning Sciences, 25, 599-633.

Scheiter, K., Schubert, C., and Schuler, A. (2018). Self-regulated learning from illustrative text: eye movement modelling to support use and regulation of cognitive processes during learning from multimedia. British Journal of Educational Psychology. 88, 80-94.

Schunk, D.H. (2012). Learning Theories: An educational perspective. $6^{\text {th }}$ ed. Pearson.

Seufert, T., Wagner, F., and Westphal, J. (2017). The effects of different levels of disfluency on learning outcomes and cognitive load. Instructional Science. 45, 221-238.

Sharif, M., Soleimani, H., and Jafarigohar, M. (2017). E-portfolio evaluation and vocabulary learning: Moving from pedagogy to andragogy. British Journal of Educational Technology. Vol. 48, No. 6, 1441-1450.

University of Dundee. (2018, November 12). Non-clinical research ethics. https://www.dundee.ac.uk/research/ethics/.

van Blanckestein, F.M., Trustescu, G.O., ven der Rijst, R.M., and Saab, N. (2019). Immediate and delayed effect of a modelling example of the application of principles of good feedback practice: a quasi-experimental study. Instructional Science. [Viewed 11 April 2019]. Available from: doi: https://doi.org/10.1007/s11251-019-09482-5.

van der Kleij, F., Adie, L., and Cumming, J. (2017). Using video technology to enable student voice in assessment feedback. British Journal of Educational Technology. Vol. 48, No. 5, 1092-1105.

Wang, Q., Ding, Y., and Yu, Q. (2018). Working memory load and automaticity in relation to problem solving in college engineering students. Journal of Engineering Education. October, Vol. 107, No. 4, 636-655.

Winne, P.H. (2018). Theorising and researching levels of processing in self-regulated learning. British Journal of Educational Psychology. 88, 9-20. 